\title{
How Self-Esteem Shapes our Interactions with Play Technologies
}

\author{
Max V. Birk, Regan L. Mandryk, Matthew K. Miller \\ University of Saskatchewan \\ Saskatoon, Canada \\ \{max.birk, regan.mandyk, matthew.miller\}@usask.ca
}

\author{
Kathrin M. Gerling \\ University of Lincoln \\ Lincoln, UK \\ kgerling@lincoln.ac.uk
}

\begin{abstract}
The experience that results from video game play is shaped by the play environment, but also by various characteristics of the person playing. We investigated how player selfesteem predicts post-game motivation (enjoyment, effort, and tension), and conducted mediated regressions to show that players' self-esteem alters post-play motivation by affecting how needs are satisfied during play. We also explored how self-esteem predicts post-play positive and negative affect and conducted mediated regressions to show how motivation partially mediates those effects. Our work suggests that players with different levels of self-esteem experience games differently; but more importantly, we provide an explanation of how these differences form by examining the mechanisms during games that ultimately contribute to player experience. Situating our results within theories of self, we discuss the importance of self-esteem for understanding player experience, describe the implications for games research, and consider how selfesteem shapes our interactions with play technologies.
\end{abstract}

\section{Author Keywords}

Player modeling; self-esteem; evaluation; serious games.

\section{ACM Classification Keywords}

K.8.0 [Personal Computing]: General - Games.

\section{INTRODUCTION}

As video games have become pervasive, researchers in multiple and diverse disciplines have been contributing to the science of games. In games user research (GUR), we are concerned with understanding the experience of players (pX); however, we generally consider the experience of a play session in isolation - that is, as disconnected from the previous life experiences that people bring with them into game play. And yet, the experience that results from computer and video game play can vary greatly depending

\footnotetext{
Permission to make digital or hard copies of all or part of this work for
} personal or classroom use is granted without fee provided that copies are not made or distributed for profit or commercial advantage and that copies bear this notice and the full citation on the first page. Copyrights for components of this work owned by others than ACM must be honored. Abstracting with credit is permitted. To copy otherwise, or republish, to post on servers or to redistribute to lists, requires prior specific permission and/or a fee. Request permissions from Permissions@acm.org.

CHI PLAY 2015, October 03-07, 2015, London, United Kingdom (C) 2015 ACM. ISBN 978-1-4503-3466-2/15/10 ..\$15.00

DOI: http://dx.doi.org/10.1145/2793107.2793111 on a player's life experience - both in terms of the context resulting from their situation at the moment of play (i.e., states), and the type of person who they are in general (i.e., traits). For example, individuals who enter into game play when in a state of ego-depletion - a state of reduced selfcontrol from having exerted effort and willpower - are more likely to negatively appraise their time spent playing games, feel guilt over having played, and profit less from the demonstrated benefits of games [33]. Also, individuals who have low satisfaction of their basic psychological needs in life experience less enjoyment, more tension, and higher negative affect post-play [32]; this type of engagement with games is characterized as an obsessive passion [32]. An aspect to be considered in this context is that low self-esteem is linked to lower satisfaction of psychological needs, to lower self-regulation, and to a propensity toward obsessive passion, suggesting that the positive outcomes that games can have on well-being are threatened for people with low self-esteem [22].

If we can better understand the mechanisms within the game experience itself that drive negative post-play outcomes for people low in self-esteem, we may be able to improve $\mathrm{pX}$ for this group through adapted game design, allowing them to obtain the full benefits of play on wellbeing. However, we must first confirm that low self-esteem is related to negative play experience and then understand the mechanism through which play experience is affected by self-esteem. To this end, we conducted a study with 125 players of a side-scrolling shooter game with manipulated leaderboards. We measured post-play experience after each game round in terms of mood (negative and positive affect) and motivation (enjoyment, effort, tension). We also measured how each round satisfied the players' in-game needs of competence, autonomy, relatedness, presence, and intuitive control. We investigated how self-esteem predicts post-game motivation and conducted mediation analyses to show that players' self-esteem alters post-play motivation by affecting how needs are satisfied during play. We also explored how self-esteem predicts post-play affect and conducted a mediation analysis to show how post-play motivation mediates these effects.

Our results reveal four main findings: (1) higher self-esteem predicts increased enjoyment and effort and decreased tension; (2) these relationships are mediated by need satisfaction - in particular through increases to autonomy, 
presence, and intuitive control for enjoyment and effort, and through decreases in relatedness and intuitive control, but increases in presence for tension; (3) increases in selfesteem predict increased positive affect and decreased negative affect; and (4) the relationship between selfesteem and positive affect is partially mediated by increases in enjoyment and effort and the relationship between selfesteem and negative affect is partially mediated by decreases in tension. In other words, our work shows that players with different levels of self-esteem experience games differently; but more importantly, we provide an explanation of how and why these differences form by examining the mechanisms within play that contribute to experienced affect and motivation, contributing to a better understanding of the effects of player traits such as selfesteem on player experience.

Our results provide richness to the theoretical models of how different players experience games - an important step in advancing the state of GUR. However, our work also has implications in human-computer interaction (HCI) beyond this knowledge. In particular, researchers and designers should understand the effects that self-esteem has on $\mathrm{pX}$ because we use games for many different purposes - both playful and serious, such as games for treating depression [36], encouraging exercise [23], and aiding persons with disabilities and chronic conditions [17]. In many cases, the populations targeted by serious games are people with lower self-esteem [17], and our findings suggest that the people for whom serious games are designed may not benefit as much as intended because of the influence of self-esteem on play experience. In addition, our work has implications in a multiplayer context if players with low self-esteem do not feel related during play, as it can increase experienced tension and negative affect, which may lead to aggressive behaviour [5] and contribute to toxicity in multiplayer game environments [44]. Finally, researchers should have knowledge of the self-esteem of their game study participants to ensure that measured play experience changes (e.g., to enjoyment or affect) as a result of an experimental manipulation are not actually explained by differences in self-esteem.

In HCI, we study how humans interact with technology; however, we often reduce people to a representation of their cognitive or motor abilities, conceptualizing people as users. Self-esteem is part of our core - a personal aspect comprised of the sum of our life experiences that shapes how we interact with technology. Our work begins to consider its role within the context of player experience.

\section{RELATED WORK}

This section summarizes existing research in the areas of player engagement, individual differences for players, and how self-esteem and the self affect player experience.

\section{Understanding Player Engagement}

Video games are currently a very successful product in the entertainment market, and several theories have tried to explain why we indulge in media consumption. Mood management theory, for example, states that we use media to regulate our arousal and affective state [47]. The application of Self-determination Theory [37] to play provides a well-grounded theoretical framework that allows us to explain why people play, and how their experience changes based on the satisfaction of needs. The traditional model proposes three needs [38]: Competence is the need to experience mastery and control over the outcome of a challenge, e.g., having a clear objective in a game; Autonomy is defined as the need to engage in a challenge under one's own volition, e.g., selecting challenges that are in-line with our personal perception of challenge; Relatedness is the universal need to feel connected to others, e.g., playing a game with friends. The Player Experience of Needs Satisfaction Scale (PENS) [37] was developed to assess these constructs in video games, adding Presence/Immersion, the experience of being transported into a virtual environment; and Intuitive Control, describing the naturalness of the game input used.

The Intrinsic Motivation Inventory (IMI) was recently adapted for application in game contexts [27]. The IMI considers constructs related to intrinsic motivation within gameplay, including: interest-enjoyment, pressuretension, competence, and effort-importance as four aspects of intrinsic motivation. The Positive Affect/ Negative Affect Scale (PANAS) focuses on quantifying positive affect and negative affect [46] and has been used to measure affective states arising from gameplay [3]. The concepts of need satisfaction, intrinsic motivation, and affect are all relevant in the context of gameplay, and although the relationships among them can be complex, research has demonstrated that the satisfaction of needs is predictive of intrinsic motivation and affective changes in video games [37]. However, these constructs can also affect people differently based on their demographic traits (e.g., age or sex) or traits that reflect their personality or character, which we explore next.

\section{Different Player Groups and Player Experience}

Previous work has explored relationships between individual player traits and the way that different types of people experience games. Research suggests that there may be individual differences in player experience between groups of players, for example, older adults having different perceptions of multiplayer games [9] and people from different cultures experiencing persuasive games differently [16] Other research on games for health shows that individual differences between players in terms of their play style not only affect their experience, but also extend to how messages conveyed by games are perceived [28].

Moving beyond demographic factors, research has also investigated the role that personality has on player 
experience. A study by Johnson and Gardner [15] examined relationships between player personality and player experience, demonstrating that personality traits moderate the way we experience games. Additionally, recent research on player modeling has shown that personality moderates the way in which needs satisfaction influences enjoyment and effort in play [4]. Although personality is generally characterized by the five-factor model [14], there are other ways of describing a person's character that are also important for player experience evaluation; the concepts of self-efficacy [20] and self-discrepancy [2] are also important for GUR.

For example, Przybylski et al. [31] showed that convergence between ourselves within the context of a game (i.e., game-self) and how we want to be in real-life (i.e., ideal-self) is predictive for intrinsic motivation. Birk and Mandryk [3] showed that self-discrepancy in personality traits is a valuable tool for needs satisfaction during play and ultimately for understanding player experience. This research shows that the experience that players have with games is highly individual and moderated by personality and other more personal factors, such as how players feel about themselves.

\section{Understanding Self-Esteem and User Experience}

Based on different roles we take in life, e.g., policeman, teacher, or researcher, we develop answers to the question of who we are; this so called self-concept is not only tied to professional roles, but is also defined by our roles in other areas of our lives, e.g., in our family, athletic, or intellectual environment. While self-concept refers to the different roles we define ourselves by, self-esteem attaches values to these roles, e.g., doing a great job at parenting, being a good athlete, or feeling incompetent in one's job [42].

Research on self-esteem from the perspective of SDT has identified two different aspects of self-esteem, both dependent on the satisfaction of our basic need for autonomy [6]. True self-esteem is defined as a deep sense of a feeling of being worthy and is related to the experience of high levels of satisfaction of autonomy. In contrast, contingent self-esteem is a superficial form of self-esteem and depends on matching criteria such as performing up to an achievement standard [42]. Heppner [13] evaluated the relation between need satisfaction and self-esteem on a daily basis, and showed that need satisfaction is related to higher self-esteem. True self-esteem is increased when "who we are", (i.e., actual self) is in line with who we want to be, (i.e., ideal self) [19], leading to actions that are truly important to the individual. Discrepancy between our actual self and our ideal self has been demonstrated to be relevant for player-character relations [1], and player experience [3].

Based on Vallerand's [42] definition of harmonious passion (HP) as showing behavior under one's own volition, and obsessive passion (OP) as engaging in a behavior to live up to an external standard of validation, Mageau et al. showed that HP and OP relate to self-esteem [26]. They showed that players with OP rely more heavily on their passionate activity to derive self-esteem compared to people with HP, which can lead to lower positive affect and lower levels of autonomy. Additionally, they showed that self-esteem is tied to game performance for people who play with OP, but not for those playing with HP. Wang et al. [45] also linked passion to video games, showing that players with greater passion reported greater positive affect after playing. Przybylski et al. [32] showed that playing under OP leads to a negative perception of game experiences, such as lower game enjoyment and greater post-play tension. Additionally, this work suggests that the negative emotions associated with losing extend beyond play, affecting perceived competence, and feeding into aggression demonstrated outside the gaming context.

In the context of player experience, results by Klimmt et al. [21] show that expertise influences player experience, suggesting that how competent players expect to be at a certain game has an impact on how they evaluate success or failure. Finally, Gerling et al. [10] showed that the emphasis of skill disparity between players in co-located competitive video games leads to lower levels of self-esteem.

This is important for our research, because we are interested in the effects of self-esteem within the context of a game, shifting the perception of gaming from an experience that is isolated from the player themselves to one that integrates the needs, traits, and context of the player.

\section{STUDY: EXPLORING THE RELATIONSHIP BETWEEN SELF, PLAYER PERFORMANCE, AND EXPERIENCE}

In this study, we explore the relationship between selfconcepts, player performance, and experience in an online experiment based on a game that manipulated $\mathrm{pX}$.

\section{Gaming System: Batcave}

Batcave is a side-scrolling shooter game in which players ride a flying mine cart through a tunnel while having to avoid obstacles and fight enemies in order to reach the treasure cavern (Figure 1). The game was implemented in C\# using Unity 3D (unity3d.com), and deployed online.

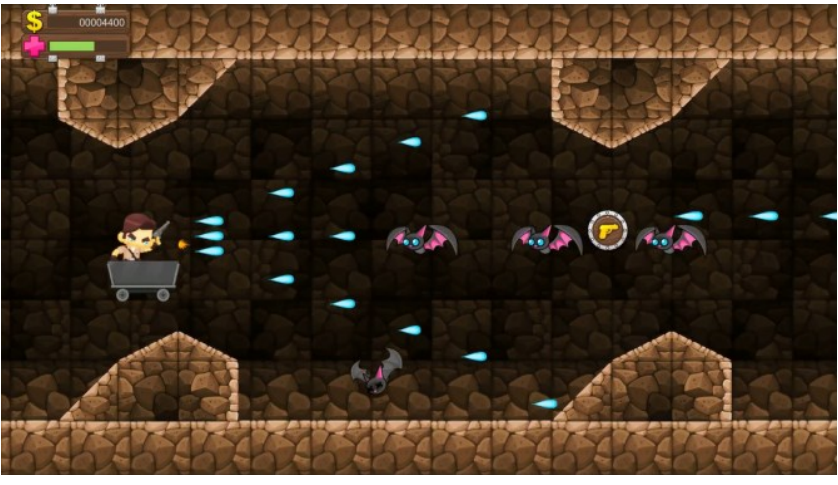

Figure 1. A player firing the special shot in Batcave. 
Gameplay. Players ride the flying mine cart through the tunnel and have control over two actions: vertical movement and firing the gun; the cart moves at a constant rate. Players must avoid three kinds of obstacles: the stalagmites and stalactites; the flying or walking enemies, and the rocks that the walking enemies throw toward the player. Shooting the enemies or the rocks eliminates them and increases the player's score; shooting the stalagmites and stalactites does no damage. Additionally, a collectable weapon power-up is presented depending on the score. Collecting this power-up changes the visuals of the bullets that are shot, but does not actually alter damage properties, to provide a similar level of challenge for all players. Damage properties of the weapon are only adjusted after players have collected three consecutive power-ups, leading to a special shot that fires three bullets at the same time in a fanned pattern. Players start the game with full health; hitting obstacles or getting hit by enemies decreases health (the player's avatar flashes). To further increase challenge, players lose the most recent power-up after 10 collisions with enemies or obstacles (at which point, health resets to full power). To give participants a sense of closure at the end of the game, a bonus cavern with collectable gems is presented, which add to the score of the player.

Controls. Shots are fired using the space key, and players can move up and down on the horizontal axis using the up and down arrows. Players' vertical position stays fixed while the background is scrolling by, using a mechanic commonly applied in rail shooting games. This restriction allows us to keep game duration constant, thereby exposing each participant to exactly 2:30 minutes of gameplay.

\section{Leaderboard Manipulation}

Batcave implements a leaderboard manipulation to allow us to control for the effects of game outcome on player experience. At the beginning of the game, players are asked to enter a username. To create a sense of competition, players move into a virtual lobby with their user name displayed below a picture of a neutral avatar. The lobby is prepopulated with three to nine virtual players with pregenerated user names; additional players are added every 1.7 seconds, until there are 12 players. To manipulate game outcome (i.e., success and failure), a leaderboard is presented at the end of each game round. This board displays the player in the first place (positive), between the $5^{\text {th }}$ and the $8^{\text {th }}$ place (neutral), or at the $11^{\text {th }}$ place (negative). The scores of the virtual players are generated based on the player's score to create one of three predetermined outcomes. To maintain the illusion of competition, a loading screen "retrieving other players' scores" is displayed before the leaderboard is presented.

We included the leaderboard manipulation to standardize the sense of relative performance across all players and to make the game feel more like a true game experience than an experiment that uses a game. Although we cannot fully replicate the sense of playing under one's own volition in an experimental context, our game design choices are intended to best balance between the control needed to create models of $\mathrm{pX}$ and the autonomy needed to feel like one is truly immersed in a game.

\section{Measures}

This section gives an overview of measures that we applied in our study. To secure comparability between all scales, composite scores were created and z-standardized [11].

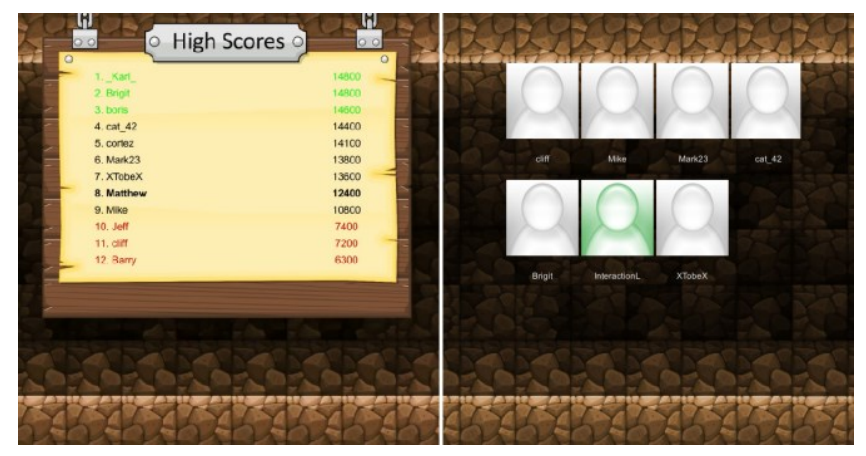

Figure 2. Neutral leaderboard (left) and player lobby (right).

\section{Rosenberg Self-Esteem Scale}

Self-esteem was assessed using the Rosenberg Self-Esteem Scale [35], which is commonly used in psychology, and has been applied in GUR [10]. The scale consists of ten statements exploring participant perceptions of themselves, e.g., "All in all, I am inclined to feel that I am a failure", or "I am able to do things as well as most other people". Participants are asked to rank these statements on a 4-point scale ranging from 1 ("strongly disagree") to 4 ("strongly agree"). The scale does not offer a neutral option.

\section{Player Experience}

Need Satisfaction was assessed using the 21-item Player Experience of Need Satisfaction (PENS) scale. Participants were instructed to reflect on their experience and rate a series of statements on a 5-point Likert scale. Intrinsic Motivation was assessed using the 18-item Intrinsic Motivation Inventory (IMI) [27]. Participants were instructed to indicate their agreement with a series of statements using a 5-point Likert scale. Positive Affect and Negative Affect were assessed using the 20-item version of the Positive Affect Negative Affect Schedule-Expanded (PANAS-X) [46]. Participants indicated agreement with feelings and adjectives on a 5-point Likert scale.

\section{Performance Metrics}

To gain insights into player performance, we logged ingame performance metrics for each round.

\section{Game Ability}

We measured game ability using a modified version of the Self-Attribution questionnaire [30], which asks players to rate their attitudes about their abilities and activities, e.g., intellectual ability, and social skills; however, we instead asked players about their game ability. 


\begin{tabular}{|c|c|c|c|c|c|c|c|c|c|c|c|c|c|}
\hline & $\mathrm{M}$ & SD & 1 & 2 & 3 & 4 & 5 & 6 & 7 & 8 & 9 & 10 & 11 \\
\hline 1. Self-Esteem & 31.57 & 5.38 & - & & & & & & & & & & \\
\hline 2. Competence & 3.77 & 0.77 & $.340^{\star *}$ & - & & & & & & & & & \\
\hline 3. Autonomy & 2.8 & 1.1 & $.293^{* *}$ & $.395^{* *}$ & - & & & & & & & & \\
\hline 4. Relatedness & 2.4 & 0.89 & $.302^{* *}$ & $.377^{* *}$ & $.574^{* *}$ & - & & & & & & & \\
\hline 5. Presence & 2.5 & 0.99 & $.217^{* *}$ & $.419^{* *}$ & $.743^{* *}$ & $.707^{* *}$ & - & & & & & & \\
\hline 6. Intuitive Controls & 4.29 & 0.67 & $.177^{* *}$ & $.329^{* *}$ & .054 & -.079 & .017 & - & & & & & \\
\hline 7. Tension & 3.51 & 0.96 & $-.124^{*}$ & $-.185^{* *}$ & .076 & .007 & $.173^{* *}$ & $-.196^{* *}$ & - & & & & \\
\hline 8. Enjoyment & 3.87 & 0.89 & $.231^{* *}$ & $.398^{* *}$ & $.718^{* *}$ & $.466^{* *}$ & $.670^{* *}$ & $.203^{* *}$ & .006 & - & & & \\
\hline 9. Effort & 2.49 & 0.97 & $.279^{* *}$ & $.334^{* *}$ & $.473^{* *}$ & $.286^{\star *}$ & $.428^{* *}$ & $.305^{* *}$ & $.151^{* *}$ & $.617^{\star *}$ & - & & \\
\hline 10. Positive Affect & 3.24 & 1.04 & $.367^{* *}$ & $.439^{* *}$ & $.578^{* *}$ & $.418^{* *}$ & $.570^{* *}$ & $.180^{* *}$ & .018 & $.634^{* *}$ & $.620^{* *}$ & - & \\
\hline 11. Negative Affect & 1.27 & 0.43 & $-.205^{* *}$ & $-.115^{*}$ & .033 & -.015 & .081 & $-.224^{* *}$ & $.347^{* *}$ & $-.107^{*}$ & $-.111^{*}$ & -.020 & - \\
\hline
\end{tabular}

Table 1. Correlations between self-esteem, need satisfaction, intrinsic motivation, and positive and negative affect, *p<.05; **p<.01

\section{Participants and Deployment Platform}

174 participants $(46.6 \%$ female) with an average age of $31.9(S D=10.3)$ participated in our study through Amazon Mechanical Turk (MTurk), a platform that acts as a broker between parties offering a range of Human Intelligence Tasks (HITs) (e.g., marketing questionnaires, or research studies) and paid workers. Participants received $\$ 6$ compensation paid through the platform. Although it has been shown that MTurk is a reliable research tool [25], we added 26 attention questions and measured the time spent per questionnaire to evaluate task performance and ensure participants were attentive despite the online setting [18]. Participants were excluded from further analysis based on these measures; if participants made more than 5 attention errors, filled in more than 4 surveys in less than $-1 \mathrm{SD}$ of average completion time, or showed ratings of -+3SD in more than 4 questionnaires. We also filtered participants who made mention in a free-form text field asking about the purpose of the study prior to debriefing that the leaderboard manipulation was engineered. Finally, we removed three outlier participants with extremely low in-game scores ( $<4000$ before the bonus cavern). After these filters were applied, 125 participants ( $11 \%$ female) with an average age of $31.34(S D=10.23)$ were included in the analysis. Ethical approval was obtained from the University of Saskatchewan's behavioural ethics board, and participants were asked to give informed consent at the beginning of the task. To comply with ethical guidelines, the HIT was only made available to workers in the USA who were older than 18. Additionally, only workers with an approval rate above $90 \%$ were offered the HIT as a means of quality control.

\section{Procedure}

Participants first received information on task duration, compensation, expectations to work attentively and quickly, and were asked to give informed consent. Participants then entered the experimental phase; they were presented with the Rosenberg Self-Esteem Scale and the Self-Attribution Questionnaire. Next, we collected baseline affect using the PANAS questionnaire. Following the questionnaires, participants played a tutorial round of Batcave, and then Batcave was presented in three sets of two game rounds (six games in total). The first game in each set used the neutral leaderboard. The second game in the set used either the positive, neutral, or negative leaderboard, the presentation of which was fully counterbalanced across participants. After each set of two game rounds, players provided an assessment of motivation using IMI, player experience of need satisfaction using PENS, and affect using PANAS.

Following game play, we collected demographic information, asked participants to state the purpose of the study in their own words, and then forwarded participants to the debriefing stage in which we disclosed the cover story and ensured that they understood the manipulation by asking simple questions about the setup.

\section{Data Analysis}

Analysis was performed using SPSS 22. Prior to modeling, all data were z-standardized and mean centered.

We ran two sets of models. First we investigated the role of self-esteem on motivation and then we investigated the role of self-esteem on affect. In both cases, we use multiple parallel mediation regression analysis [12] to detect the effects of self-esteem on the dependent measures and to understand the role that the mediators play.

In our first set of models, we investigate the role of selfesteem on post-play motivation and we model how in-game needs satisfaction mediates these effects (the link between need satisfaction and motivation has already been well established [38]). Our predictor is always self-esteem. Our motivation dependent measures are enjoyment, effort, and tension. Our mediators are the five PENS items, applied in parallel: competence, autonomy, relatedness, presence, and intuitive control. We construct three such regression models (see Figure 3). In all models, we control for sex, game outcome, and game ability.

In our second set of models, we investigate the role of selfesteem on post-play affect and we model how motivation mediates these effects (the link between motivation and affect has been established [37]). Our predictor is selfesteem. Our dependent measures are positive affect and negative affect. In this case, however, our mediators are the 

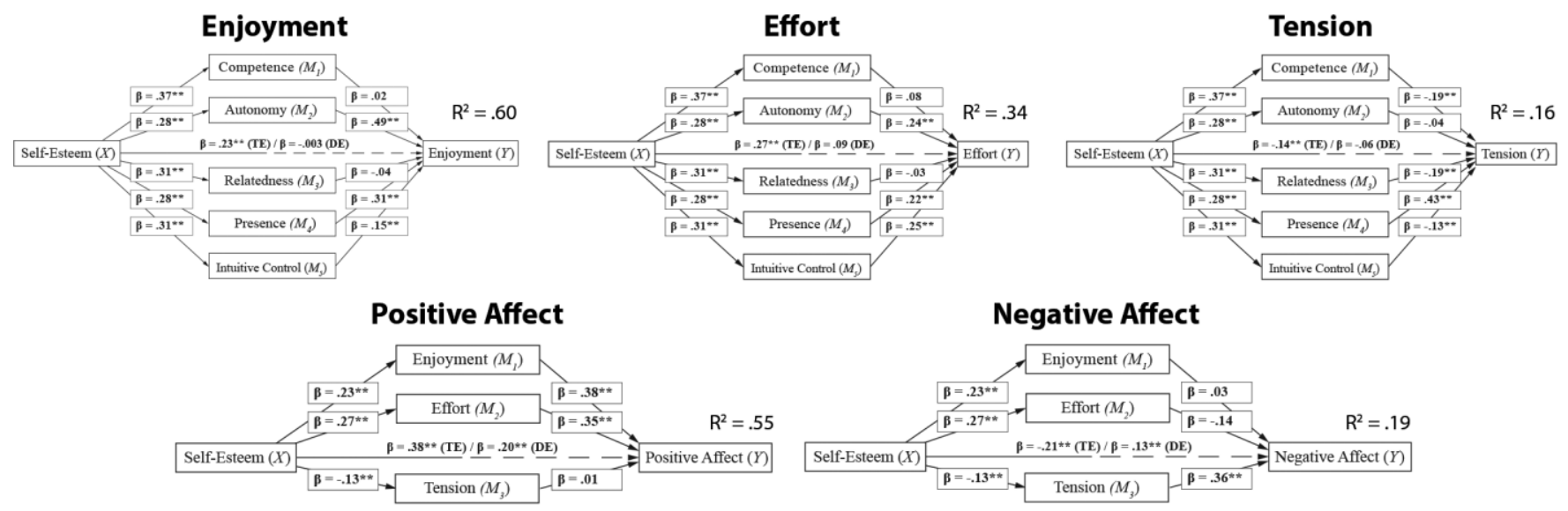

Figure 3. Diagram for the parallel mediator model including the total effect (TE) and direct effect (DE) of self-esteem on enjoyment (top-left), effort (top-middle), tension (top-right), positive affect (bottom-left), and negative affect (bottom-right); beta-coefficients for the effects of each path are included, ${ }^{*} \mathbf{p}<.05 ;{ }^{* *} \mathbf{p}<.01$, and the $\mathbf{R}^{2}$ represents the fit for the whole model.

motivation measures (enjoyment, effort, and tension), see Figure 3. We construct two such models, one for positive affect and one for negative affect

For readers unfamiliar with mediation analysis $[11,12]$, we describe it in brief here. For the purposes of illustration, we will refer to our predictor $(\mathrm{X})$ as self-esteem, our dependent measure (Y) as enjoyment, and our mediator (M) as need satisfaction. The total effect of self-esteem on enjoyment does not consider the role of the mediators (path $X \rightarrow Y$ in Figure 3 ). The direct effect considers the role of self-esteem when the mediators (the five need satisfaction measures) are also included in the model (path $\mathrm{X} \rightarrow \mathrm{M}_{\mathrm{k}} \rightarrow \mathrm{Y}$ in Figure 3 ). The indirect effect shows how the relationship between self-esteem and enjoyment operates through a reduction in the satisfaction of needs during play. The significance of the indirect effect (i.e., the mediated relationship) can be assessed using analysis of the bootstrapped confidence intervals $[11,12]$, generated using 5000 samples. There is a significant mediation, i.e., self-esteem affects enjoyment via need satisfaction, when the bootstrapped confidence intervals do not contain zero $[11,12]$.

\section{RESULTS}

We first investigated the role of self-esteem during play. The self-esteem of our sample (mean=21.47, $S D=5.15$ ) is comparable with a general sample (mean $=22.62, S D=5.80)$ [40]. We next present correlations and the mediation.

\section{Correlations}

Table 1 shows the correlations between self-esteem, the needs satisfaction measures, the motivation measures, and affect measures. Self-esteem correlates with all measures, suggesting that it plays a role in player experience. In addition, the need satisfaction variables are correlated with the motivation measures, suggesting a relationship in our data set (which has also been established in prior literature [37]). Finally, positive affect is strongly correlated with enjoyment and effort, whereas negative affect is strongly correlated with tension, suggesting those relationships in our data set.

\section{Role of Self-Esteem in Predicting Motivation}

Figure 3 shows the results for the mediated regression analysis with self-esteem [36] as the predictor (X), the motivation measures enjoyment, effort, and tension [35] as the dependent measures (Y), and the needs satisfaction measures competence, autonomy, relatedness, presence, and intuitive control [37] as the mediators $\left(\mathrm{M}_{1}-\mathrm{M}_{5}\right)$; beta values, standard error of beta (from the 5000 bootstrapped samples) and p-values are shown for each path. Table 2 shows the results of the mediation analysis using bootstrapped confidence intervals. The confidence intervals are based on a bootstrapped standard error using 5000 samples. Recall that the mediation is significant if zero is not contained within the confidence interval.

All models were built controlling for sex, game outcome, and game ability. Sex predicted enjoyment $(\beta=-.20, p=.002)$ and tension $(\beta=-.25, p=.009)$, and game ability was a significant negative predictor of invested effort $(\beta=-.089$, $p=.042$ ). No other effects were significant.

\section{Enjoyment}

We first show the total effect, i.e., that self-esteem predicts enjoyment. As shown in Figure 3, higher self-esteem predicts increased enjoyment.

Second, we show that self-esteem predicts the mediator variables. As expected, self-esteem predicts in-game need satisfaction for each of competence, autonomy, relatedness, presence, and intuitive control.

Third, we show that the indirect effect is greater than the effect of self-esteem when the mediators are not included. As Figure 3 shows, when need satisfaction was included in the model, the direct effect of self-esteem on enjoyment 
was no longer significant, but the indirect effect of selfesteem on enjoyment through the mediators autonomy, presence, and intuitive control were significant, whereas there was no mediating effect of competence or relatedness.

Together, these results show that self-esteem affects enjoyment of a game, and that this effect is mediated by the satisfaction of autonomy, presence, and intuitive control.

\section{Invested Effort}

As seen in Figure 3, higher self-esteem predicts increased effort. As with enjoyment, self-esteem predicts in-game need satisfaction for each of the five needs. Furthermore, when needs satisfaction was included in the model, the direct effect of self-esteem on effort was no longer significant, but the indirect effect of self-esteem on effort through the mediators autonomy, presence, and intuitive control was significant. Satisfaction of competence and relatedness do not mediate the role of self-esteem in predicting invested effort.

\section{Experienced Tension}

As seen in Figure 3, higher self-esteem predicts decreased tension. As with enjoyment, self-esteem predicts in-game need satisfaction for each of the five needs. When needs satisfaction was included in the model, the direct effect of self-esteem on tension was no longer significant, but the indirect effect of self-esteem on tension through the mediators competence, presence, and intuitive control was significant. Satisfaction of autonomy and relatedness do not mediate the role of self-esteem in predicting tension.

\section{Role of Self-Esteem in Predicting Affect}

Figure 3 shows the results for the mediated regression analyses with self-esteem [35] as the predictor (X), positive and negative affect [46] as the dependent measures (Y), and the motivation measures enjoyment, effort, and tension [37], as the mediators $\left(\mathrm{M}_{1}-\mathrm{M}_{3}\right)$; beta values and $\mathrm{p}$-values are shown for each path. Note that the path from selfesteem to enjoyment in Figure 4 could be replaced by the entire model for enjoyment in the top-left of Figure 4; likewise for the paths to effort and tension.

All models were built controlling for the effects of sex, game outcome, and game ability. Sex was a significant predictor of positive affect $(\beta=.21, p=.007)$ and negative affect $(\beta=.11, p=.011)$, and game ability was a significant predictor of positive affect $(\beta=.12, p=.002)$. No other effects were significant.

\section{Positive Affect}

As seen in Figure 3, higher self-esteem predicts increased positive affect. As expected based on our previous results, self-esteem also predicts enjoyment, effort, and tension. The direct effect of self-esteem on positive affect remains significant, even when the motivation measures are included in the model; however, there is also a significant mediation effect for enjoyment and effort, showing that enjoyment and effort partially mediate the relationship between self-esteem and positive affect.

\section{Negative Affect}

As seen in Figure 3, higher self-esteem predicts decreased negative affect. As expected, self-esteem also predicts enjoyment, effort, and tension. The direct effect of selfesteem on negative affect remains significant, even when the motivation measures are included in the model; however, there is also a significant mediation effect for tension, showing that tension partially mediates the relationship between self-esteem and negative affect.

Our results first show that higher self-esteem predicts increases in positive affect, enjoyment, and effort, and decreases in negative affect and tension, meaning that individual differences in self-esteem are reflected in the way we experience games.

\begin{tabular}{|c|c|c|c|c|c|c|c|c|c|}
\hline & \multicolumn{3}{|c|}{ Bootstrap Results: Enjoyment } & \multicolumn{3}{|c|}{ Bootstrap Results: Effort } & \multicolumn{3}{|c|}{ Bootstrap Results: Tension } \\
\hline & \multirow[b]{2}{*}{$\beta$ (SE) } & \multicolumn{2}{|c|}{ 95\% Confidence Interval (CI) } & \multirow[b]{2}{*}{$\beta(S E)$} & \multicolumn{2}{|c|}{ 95\% Confidence Interval (CI) } & \multirow[b]{2}{*}{$\beta$ (SE) } & \multicolumn{2}{|c|}{ 95\% Confidence Interval (CI) } \\
\hline & & Lower & Upper & & Lower & Upper & & Lower & Upper \\
\hline Competence & $.01(.02)$ & -.03 & .05 & $.03(.03)$ & -.02 & .09 & $-.07(.03)$ & -.13 & -.03 \\
\hline Autonomy & $.14(.03)$ & .08 & .2 & $.07(.02)$ & .03 & .2 & $-.01(.02)$ & -.07 & .03 \\
\hline Relatedness & $-.01(.02)$ & -.05 & .02 & $-.01(.02)$ & -.05 & .03 & $-.06(.03)$ & -.12 & -.02 \\
\hline Presence & $.07(.02)$ & .03 & .13 & $.05(.02)$ & .02 & .10 & $.09(.03)$ & .05 & .18 \\
\hline \multirow[t]{4}{*}{ Intuitive Control } & $.03(.01)$ & .01 & .06 & $.05(.02)$ & .02 & .09 & $.03(.01)$ & -.06 & -.01 \\
\hline & \multicolumn{3}{|c|}{ Bootstrap Results: Positive Affect } & \multicolumn{3}{|c|}{ Bootstrap Results: Negative Affect } & & & \\
\hline & & \multicolumn{2}{|c|}{ 95\% Confidence Interval (CI) } & & \multicolumn{2}{|c|}{ 95\% Confidence Interval (CI) } & & & \\
\hline & $\beta(S E)$ & Lower & Upper & $\beta(\mathrm{SE})$ & Lower & Upper & & & \\
\hline Enjoyment & $.09 .(.04)$ & .05 & .14 & $.01(.02)$ & -.03 & .05 & & & \\
\hline Effort & $.09(.02)$ & .06 & .15 & $-.04(.03)$ & -.10 & .01 & & & \\
\hline Tension & $-.00(.01)$ & -.01 & .01 & $-.05(.02)$ & -.10 & .01 & & & \\
\hline
\end{tabular}

Table 2. Beta-values (Standard Error) and upper and lower limits of $95 \%$ confidence intervals of Bootstrapping (5000 samples) results for the parallel mediation analysis of: Top row: self-esteem on enjoyment, effort, and tension, mediated by need satisfaction (PENS); Bottom Row: self-esteem on positive and negative affect, mediated by enjoyment, effort, and tension. 


\section{DISCUSSION}

In our work, we explore the relationship between selfesteem and player experience with the goal of determining the potential impact of low self-esteem on the way we experience games.

We then show that the relationship between self-esteem and motivation is mediated by changes in need satisfaction - in particular through increases in autonomy, presence, and intuitive control for enjoyment and invested effort, and through decreases in relatedness and intuitive control, but increases in presence for tension. In terms of affect, we show that the relationship between self-esteem and positive affect is partially mediated by increases in enjoyment and effort and that the relationship between self-esteem and negative affect is partially mediated by decreases in tension. That self-esteem affects motivation (and ultimately affect) through the satisfaction of needs suggests that the decreased experience for players with low self-esteem can be addressed at the level of game design.

In this section, we interpret the meaning of the influence of self-esteem, discuss implications for games research, and outline the relevance of our findings for enabling all groups of players to have positive play experiences.

\section{Having versus Wanting to Play}

Our results show that players with low self-esteem experience lower positive affect and higher negative affect, invest less effort, and experience more tension and less game enjoyment. These results mirror Przybylski et al. [32], who showed that people with lower levels of general needs satisfaction in life (as opposed to in-game) experienced less game enjoyment and higher negative affect post play (obsessive passion) than people with higher general life satisfaction of needs (harmonious passion).

Because self-esteem is closely linked to general life satisfaction of needs [6], our results can help explain the mechanisms by which these two patterns emerge because we gather data about how needs satisfaction during play mediates the relationship between self-esteem and post-play motivational outcomes, and ultimately also post-play affect. We show that players with low self-esteem experience less satisfaction of needs during play, which translates into less motivation. Thus a well-designed game will simply satisfy needs less and also result in less enjoyment and effort for players with low self-esteem than for those with high selfesteem. The effects on motivation cascade into effects on negative affect, which show that players lower in selfesteem experience increases in negative affect, which is partially mediated by the increased tension they experience during play. This result of dampened needs satisfaction producing less enjoyment and more negative affect for people low in self-esteem is in line with the disordered pattern of play observed in [32] that results in 'having versus wanting to play'.

\section{State Self-Esteem}

Our research examines trait self-esteem - i.e., the general self-esteem a player experiences. Ryan et al. [37] show that changes in state self-esteem from before to after play correlate with presence, enjoyment, and affect, after playing Super Mario 64 (Nintendo, 1996). In addition, changes in self-esteem predicted perceived competence. These results show how state self-esteem can also provide value as an outcome variable in a play-test; generating short-term increases of affect, and self-esteem is an indication of a positive outcome. Our results, in contrast, suggest that preexisting individual differences in self-esteem influence need satisfaction, motivation, and affect. This means that the individual background of players feeds into their player experience, an aspects that needs to be considered in Games User Research and Game Design.

\section{Implications for Games Research}

Our results provide richness to theoretical models of how different players experience games - an important step in advancing GUR. However, our work also has implications in human-computer interaction beyond this knowledge.

The models for how self-esteem affects motivation (enjoyment, effort, and tension) all show that the direct effect of self-esteem on motivation disappears when need satisfaction variables are included in the model, which has practical significance for games research. If the direct effect remained, it would imply that the link between self-esteem and motivation was immutable - e.g., that players low in self-esteem will necessarily experience less enjoyment. Because the effect is mediated by needs satisfaction, we have an opportunity to increase enjoyment (for example) for players low in self-esteem if we can find ways to satisfy their need for autonomy, presence, and intuitive control.

\section{GUR Testing}

Our results also have practical significance in the context of player experience testing environments. GUR research (both industrial and academic) often uses small numbers of participants in user studies. When assigning participants to experimental conditions and measuring player experience in order to determine the influence of an experimental factor, self-esteem can play a confounding role. For example, because self-esteem influences enjoyment, if experiment groups are not balanced for self-esteem, researchers may attribute differences in enjoyment to the experiment factor, when self-esteem is actually explaining the variance in enjoyment. Our results suggest that researchers should gather players' trait self-esteem to control for these effects.

\section{Multiplayer Experiences}

Self-esteem is considered a resilience factor in situations where our self is at threat [24], which has implications for multiplayer gaming. Playing together with others may result in social evaluation, which can be particularly stressful for players with low self-esteem [5]. Theories like sociometer theory [24], and self-determination theory [38] suggest that 
self-esteem provides us information about how well we are doing in our social contexts, such as in multiplayer games.

Competitive multiplayer games - e.g. Dota 2 (Valve, 2013), or League of Legends (Riot Games, 2009) - require the full attention of each individual player for a team to experience success. Players low in self-esteem do not feel as related to others during play, which can increase experienced tension and lead to negative affect. In the context of multiplayer games, this social tension can lead to increased aggressive behaviour [44], which is undesirable in the context of competitive multiplayer games, threatening the development of healthy player communities. However, our results also show that increasing feelings of competence can lower experienced tension, which can be achieved through good matchmaking algorithms than match players with teammates and opponents of similar skill, for example, as is done in League of Legends. Ultimately, this should result in lower negative affect in a game.

\section{Serious Games and Game Accessibility}

Games are increasingly used for serious purposes, for example, in healthcare [17], or to combat sedentary lifestyles [23]. In many cases, populations targeted by these games are also people with lower self-esteem, for example, people with chronic illness [39], children and teenagers with special needs and learning difficulties [43], or children with weight problems [8]. It is entirely possible that the audience for whom a serious game is designed will not benefit from the intervention - or at least will not benefit as much as intended - because of the influence of self-esteem on player experience. To ensure that players low in selfesteem invest effort in a serious game, (a likely prerequisite for gaining the intended value from play), and experience enjoyment in a serious game, (a motivator for the repeated play necessary to gain value from the intervention), we need to give extra consideration to fostering a sense of autonomy (e.g., through providing customizable components [34]), ensuring that controls are intuitive (e.g., through standard usability testing approaches), and support immersion (e.g., through keeping skill and challenge balanced [41] or ensuring suspense of outcome [10]).

Much research in the area of game accessibility focuses on physical access and the design of accessible game mechanics (e.g., [10]), neglecting psychological aspects. Our findings indicate that research in these areas needs to consider the impact that challenges people experience in their daily lives have on their psychological well-being, and by extension, on how they experience interactive play.

\section{LIMITATIONS AND FUTURE WORK}

There are a number of limitations to the work presented in this paper. While it has been demonstrated that MTurk is a reliable research platform for conducting user studies [25], it also has to be noted that participants took part in our research in an uncontrolled environment that may have interfered with play, an aspect that we tried to control for through attention questions and outlier analysis. Additionally, the game included in our study is a casual side-scrolling shooter. Future research should explore whether the effects that we observed also hold when participants play games with more depth (e.g., a stronger narrative), or games that fall into different genres. Furthermore, as Figure 3 shows, the model fits of the negative aspects of $\mathrm{pX}-$ i.e., tension and negative affect are lower than those of the positive aspects. This is not unexpected, because the motivational model of need satisfaction predicts engagement in game play, and it is not clear that the absence of engagement necessarily leads to a negative experience. Finally, our results show that stimulation of relatedness in not mediating the link between self-esteem and effort or enjoyment. It is possible that the lack of importance of relatedness is an artifact of our game and environment (which had no player-player interaction) and not a true estimation of the importance of relatedness satisfaction for the influence of self-esteem on motivation. Future research should investigate the role of self-esteem in multiplayer competitive and cooperative games.

\section{CONCLUSION}

Our work adopts a broader view of player experience: along with understanding the core of games and their impact on players, we focus on the core of players - conceptualized through self-esteem - and how it influences the experience that interactive play evokes. We show that self-esteem has a profound impact on the interaction with games, extending beyond player experience and affecting emotional state, and we outline challenges for game design.

On a broader scale, our results have implications for the games research community. GUR has made large contributions to considering the physical and psychomotor abilities of players, and have successfully addressed many design-related challenges to increase player enjoyment. Recently, researchers have started to consider how the characteristics that we bring with us into play - our personality, the satisfaction of our basic needs - affect our play experiences. Our results suggest that we need to continue in this vein and extend our focus to include psychological predispositions of players to continue to develop a comprehensive, human-centric design approach to GUR that entails all aspects of human nature. Our work contributes to the understanding of how core aspects of ourselves influence interactive play, helping to ensure that playful applications positively influence people's lives through truly enjoyable and engaging experiences.

\section{ACKNOWLEDGMENTS}

We thank the GRAND NCE and NSERC for funding and members of the Interaction Lab at the University of Saskatchewan for support. We thank our participants, the reviewers who gave us feedback, and DJ Koze for the loops and Metric for the lyrics. 


\section{REFERENCES}

1. Abuhamdeh, S., Csikszentmihalyi, M., \& Jalal, B. (2015). Enjoying the possibility of defeat: Outcome uncertainty, suspense, and intrinsic motivation.

Motivation and Emotion, 39(1), 1-10.

2. Bessière, K., Seay, A. F., \& Kiesler, S. (2007) The ideal elf: Identity exploration in World of Warcraft. CyberPsychology \& Behavior 10, 4, 530-535.

3. Birk, M., \& Mandryk, R.L. (2013). Control your gameself: effects of controller type on enjoyment, motivation, and personality in game. In Proc. of CHI'13, 685-694.

4. Birk, M.V., Toker, D., Conati, C., \& Mandryk, R. (2015). Modeling Motivation in a Social Network Game using Player-Centric Traits and Personality Traits. In Proc. of UMAP'15, 18-30.

5. Berkowitz, L. (1998). Affective aggression: The role of stress, pain, and negative affect.

6. Deci, E. L., \& Ryan, R. M. (1995). Human autonomy. In Efficacy, Agency, and Self-Esteem, 31-49.

7. Dumont, M., \& Provost, M. A. (1999). Resilience in adolescents: Protective role of social support, coping strategies, self-esteem, and social activities on experience of stress and depression. Journal of Youth and Adolescence, 28(3), 343-363.

8. French, S., Story, M., \& Perry, C. (2012). Self-Esteem and Obesity in Children and Adolescents: A Literature Review. Obesity Research, 3, 5, 479-490.

9. Gajadhar, B. J., Nap, H. H., de Kort, Y. A., \& IJsselsteijn, W. A. (2010). Out of sight, out of mind: coplayer effects on seniors' player experience. In Proc. of FuGa'10, 74-83.

10. Gerling, K.M., Miller, M., Mandryk, R.L., Birk, M., and Smeddinck, J. (2014). Effects of Balancing for Physical Abilities on Player Performance, Experience and SelfEsteem in Exergames. In Proc. of CHI'14, 2201-2210.

11. Field, A. (2013). Discovering statistics using IBM SPSS statistics. Sage.

12. Hayes, A. F. (2008). Introduction to mediation, moderation, and conditional process analysis: $A$ regression-based approach. Guilford Press.

13. Heppner, W.L., Kernis, M.H., Nezlek, J.B., Foster, J., Lakey, C.E., \& Goldman, B.M. (2008). Within-person relationships among daily self-esteem, need satisfaction, and authenticity. Psychological Science, 19, 11, 1140-1145.

14. John, O. P., \& Srivastava, S. (1999). The Big Five trait taxonomy: History, measurement, and theoretical perspectives. Handbook of personality: Theory and research, 2, 102-138.

15. Johnson, D., \& Gardner, J. (2010). Personality, motivation and video games. In Proc. of OZCHI'10, 276279.
16. Khaled, R., Barr, P., Fischer, R., Noble, J., \& Biddle, R. (2006). Factoring culture into the design of a persuasive game. In Proc. of OZCHI'06, 213-220.

17. Kato, P. Video Games in Health Care: Closing the Gap. Review of General Psychology 14, 2 (2010), 113-121.

18. Kittur, A., Chi, E. H., \& Suh, B (2008). Crowdsourcing user studies with Mechanical Turk. In Proc. of CHI'08, 453-456.

19. Kernis, M. H. (2003). Toward a conceptualization of optimal self-esteem. Psychological Inquiry, 14(1), 1-26.

20. Klimmt, C., \& Hartmann, T. (2006). Effectance, SelfEfficacy, and the Motivation to Play Video Games. In Playing video games: Motives, responses, and consequences, 133-145.

21. Klimmt, C., Blake, C., Hefner, D., Vorderer, P., and Roth, C. (2009). Player Performance, Satisfaction, and Video Game Enjoyment. In Proc. of ICEC 2009, 1-12.

22. Lafrenière, M. A. K., Bélanger, J. J., Sedikides, C., \& Vallerand, R. J. (2011). Self-esteem and passion for activities. Personality and Individual Differences, 51(4), 541-544.

23. Lanningham-Foster, L., Foster, R., McCrady, S., Jensen. T., Mitre, N., \& Levine, J. (2009). Activity-Promoting Video Games and Increased Energy Expenditure. The Journal of Pediatrics 154, 6, 819-823.

24. Leary, M. R., \& Baumeister, R. F. (2000). The nature and function of self-esteem: Sociometer theory. Advances in Experimental Social Psychology, 32, 1-62.

25. Mason, W., \& Suri, S. (2012). Conducting behavioral research on Amazon's Mechanical Turk. Behavior Research Methods, 44(1), 1-23.

26. Mageau, G. A., Carpentier, J., \& Vallerand, R. J. (2011). The role of self-esteem contingencies in the distinction between obsessive and harmonious passion. European Journal of Social Psychology, 41(6), 720-729.

27. McAuley, E., Duncan, T., \& Tammen, V. V. (1989). Psychometric properties of the Intrinsic Motivation Inventory in a competitive sport setting: A confirmatory factor analysis. Research Quarterly for Exercise and Sport, 60, 48-58.

28. Orji. R., Mandryk, R., Vassileva, J., \& Gerling, K. (2013). Tailoring Persuasive Health Games to Gamer Type. In Proc. of CHI'13, 2467-2476.

29. Peng, W., Lin, J. H., Pfeiffer, K. A., \& Winn, B. (2012). Need satisfaction supportive game features as motivational determinants: An experimental study of a self-determination theory guided exergame. Media Psychology, 15(2), 175-196.

30.Pelham, B. W., \& Swann, W. B. (1989). From selfconceptions to self-worth: on the sources and structure of global self-esteem. Journal of Personality and Social Psychology, 57(4), 672. 
31. Przybylski, A. K., Weinstein, N., Murayama, K., Lynch, M. F., \& Ryan, R. M. (2012). The Ideal Self at Play The Appeal of Video Games That Let You Be All You Can Be. Psychological Science, 23(1), 69-76.

32. Przybylski, A. K., Weinstein, N., Ryan, R. M., \& Rigby, C. S. (2009). Having to versus wanting to play: Background and consequences of harmonious versus obsessive engagement in video games. CyberPsychology \& Behavior, 12(5), 485-492.

33. Reinecke, L., Hartmann, T., \& Eden, A. (2014). The Guilty Couch Potato: The Role of Ego Depletion in Reducing Recovery Through Media Use. Journal of Communication, 64(4), 569-589.

34. Rigby, S., \& Ryan, R. M. (2011). Glued to Games: How Video Games Draw Us In and Hold Us Spellbound. ABC-CLIO.

35. Rosenberg, M. (1989). Society and the adolescent selfimage (rev). Wesleyan University Press.

36. Rosenberg. D., Depp, C., Vahia, I., Reichstadt, J., Palmer, B., Kerr, J., Norman, G., \& Jeste, D. (2010). Exergames for Subsyndromal Depression in Older Adults: A Pilot Study of a Novel Intervention. The American Journal of Geriatric Psychiatry, 18( 3), 221-226.

37. Ryan, R.M., Rigby, C.S., \& Przybylski, A. (2006). The motivational pull of video games: A self-determination theory approach. Motivation and Emotion, 30(4), 344360 .

38. Ryan, R. M., \& Deci, E. L. (2000). Self-determination theory and the facilitation of intrinsic motivation, social development, and well-being. American Psychologist, $55(1), 68$.

39. Seigel, W. M., Golden, N. H., Gough, J. W., Lashley, M. S., \& Sacker, I. M. (1990). Depression, self-esteem, and life events in adolescents with chronic diseases. Journal of Adolescent Health Care, 11(6), 501-504.

40. Sinclair, S.J., Blais, M.A., Gansler, D.A., Sandberg, E., Bistis, K., \& LoCicero, A. (2010). Psychometric properties of the Rosenberg Self-Esteem Scale: overall and across demographic groups living within the United States. Evaluation \& the Health Professions, 33(1), 5680.

41. Sweetser, P., and Wyeth, P. (2005). GameFlow: A Model for Evaluating Player Enjoyment in Games. Computers in Entertainment, 3, 3.

42. Vallerand, R. J., Blanchard, C., Mageau, G. A., Koestner, R., Ratelle, C., Léonard, M., \& Marsolais, J. (2003). Les passions de l'ame: on obsessive and harmonious passion. Journal of Personality and Social Psychology, 85(4), 756.

43. Valås, H. (1999). Students with learning disabilities and low-achieving students: Peer acceptance, loneliness, self-esteem, and depression. Social Psychology of Education, 3(3), 173-192.

44. Warburton, W. A., Williams, K. D., \& Cairns, D. R. (2006). When ostracism leads to aggression: The moderating effects of control deprivation. Journal of Experimental Social Psychology, 42(2), 213-220.

45. Wang, C. K. J., Khoo, A., Liu, W. C., \& Divaharan, S. (2008). Passion and intrinsic motivation in digital gaming. CyberPsychology \& Behavior, 11(1), 39-45.

46. Watson, D., \& Clark, L. A. (1999). The PANAS-X: Manual for the positive and negative affect scheduleexpanded form.

47.Zillmann, D. (1988). Mood management: Using entertainment to full advantage. Communication, Social Cognition, and Affect, 147-171. 